This item was submitted to Loughborough's Research Repository by the author.

Items in Figshare are protected by copyright, with all rights reserved, unless otherwise indicated.

\title{
Monitoring eating and activity: Links with disordered eating, compulsive exercise and general wellbeing among young adults
}

\section{PLEASE CITE THE PUBLISHED VERSION}

https://doi.org/10.1002/eat.22966

\section{PUBLISHER}

(c) Wiley

\section{VERSION}

AM (Accepted Manuscript)

\section{PUBLISHER STATEMENT}

This is the peer reviewed version of the following article: PLATEAU, C.R. ... et al., 2018. Monitoring eating and activity: Links with disordered eating, compulsive exercise and general wellbeing among young adults. International Journal of Eating Disorders, 51(11), pp. 1270-1276, which has been published in final form at https://doi.org/10.1002/eat.22966. This article may be used for non-commercial purposes in accordance with Wiley Terms and Conditions for Use of Self-Archived Versions

\section{LICENCE}

CC BY-NC-ND 4.0

\section{REPOSITORY RECORD}

Plateau, Carolyn, Sarah Bone, Emily Lanning, and Caroline Meyer. 2019. "Monitoring Eating and Activity: Links with Disordered Eating, Compulsive Exercise and General Wellbeing Among Young Adults". figshare. https://hdl.handle.net/2134/35114. 
Monitoring eating and activity: Links with disordered eating, compulsive exercise and general wellbeing among young adults

\author{
Carolyn R Plateau, $\mathrm{PhD}^{1}$ \\ Sarah Bone, BSc ${ }^{1}$ \\ Emily Lanning, $\mathrm{BSc}^{1}$ \\ Caroline Meyer, $\mathrm{PhD}^{2}$
}

${ }^{1}$ National Centre for Sport and Exercise Medicine, School of Sport, Exercise and Health
Sciences, Loughborough University, Loughborough, LE11 3TU, UK.
${ }^{2}$ WMG, University of Warwick, Coventry, CV4 7AL, UK.
*Corresponding author: Dr Carolyn Plateau, National Centre for Sport and Exercise
Medicine, School of Sport, Exercise and Health Sciences, Loughborough University,
Loughborough, LE11 3TU. Phone: (+44) 1509228487 Email: C.R.Plateau @lboro.ac.uk

This version of the manuscript that has been accepted for publication in the International Journal of Eating Disorders (19 ${ }^{\text {th }}$ September 2018)

Please cite this article as:

Plateau, C.R., Bone, S., Lanning, E., \& Meyer, C. (in press). Monitoring eating and activity: Links with disordered eating, compulsive exercise and general wellbeing among young adults. International Journal of Eating Disorders. 


\title{
Monitoring eating and activity: Links with disordered eating, compulsive exercise and general wellbeing among young adults.
}

\begin{abstract}
Objective: To explore the relationships between the use of food intake and activity monitoring tools with compulsive exercise, eating psychopathology and psychological wellbeing. Methods: Participants $(\mathrm{N}=352$; mean age 21.90 years $)$ indicated their use of activity and food intake monitoring tools, and completed the Compulsive Exercise Test (CET), Eating Disorders Examination Questionnaire (EDE-Q) and the Warwick Edinburgh Mental Wellbeing Scale (WEMWBS). Results: Users of monitoring tools reported significantly higher CET and EDE-Q scores than non-users. Positive associations were detected between the frequency of activity monitoring tool use with CET and EDE-Q scores. Participants who reported using monitoring tools primarily to manage weight and shape reported higher levels of eating and compulsive exercise psychopathology than those who reported using tools to improve health and fitness. Discussion: Features of compulsive exercise and eating psychopathology are elevated among users of food intake and activity monitoring tools; and particularly among those who report using the tools for weight and shape purposes. Longitudinal and experimental research is needed to further our understanding of these observed associations, and specifically to explore the prospective relationships between monitoring tool use, eating psychopathology and compulsive exercise.
\end{abstract}

Key words: Disordered eating, calorie counting, tracking apps, mental health, compulsive exercise 


\section{Monitoring eating and activity: Links with disordered eating, compulsive exercise and general wellbeing among young adults}

The use of activity and food intake monitoring tools is on the rise, particularly among young adults (e.g., Krebs \& Duncan, 2015). Many smartphones now come with inbuilt health monitors (e.g., iPhone Health); whilst sales of activity monitoring devices are also significantly on the rise (e.g., International Data Corporation, 2016). Exercise and food intake monitoring apps are some of the most popular on the market, with $31 \%$ of smartphone owners using apps to monitor their diet and 38\% using them to track their exercise (Fox \& Duggan, 2012). Motivation to continue use is enhanced by certain features, including the ability to keep detailed records of exercise and food intake and the ability to interact with other users (Lee \& Cho, 2016). Apps and other monitoring tool devices are viewed as potentially useful tools for promoting behavior change; for example, increasing physical activity (Alley et al., 2016) and facilitating healthy diets (De Cock et al., 2017; Sarcona, Kovacs, Wright \& Williams, 2017).

The premise behind many devices and apps is in their ability to facilitate selfmonitoring; a technique that can be an effective mechanism for behavior change, particularly for physical activity and weight loss (e.g., Samdal, Eide, Barth, Williams and Meland, 2017). Self-monitoring is thought to increase self-awareness and elicit behavioral change by providing continuous updates on progress towards a specific goal (Carver \& Scheier, 1982). However, engaging in monitoring of food intake and exercise is not necessarily beneficial for everyone. Indeed, eating disorders (ED) are often characterized by obsessive behaviors towards food (e.g., calorie counting), perfectionistic tendencies (e.g., Bardone-Cone et al., 2007; Fairburn, Cooper \& Shafran, 2003) and rigid attitudes towards exercise (e.g., Meyer et al., 2016); cognitions and behaviors which could potentially be exacerbated by engaging with monitoring tools. 
Indeed, a small number of studies have started to explore associations between monitoring tool use with some aspects of eating psychopathology. For example, elevated levels of eating psychopathology have been reported among users of calorie-tracking tools compared to non-users (specifically dietary restraint and concern about eating; Simpson \& Mazzeo, 2017), whilst exercise monitoring has been identified as a unique predictor of eating disorder symptoms (Simpson and Mazzeo, 2017). Body dissatisfaction (a known risk factor for disordered eating; e.g., Neumark-Sztainer, Paxton, Hannah, Haines \& Story, 2006) has also been reported to be elevated among those using food intake monitoring tools (Embacher, McGloin \& Aitken, 2018). In clinical settings, a large proportion of patients not only use calorie counting tools (e.g., My Fitness Pal), but also perceive the use of such tools to have contributed towards their eating disorder symptoms (Levinson, Fewell \& Brosof, 2017). Disturbances in exercise attitudes and wellbeing commonly co-occur alongside eating disorder symptoms (e.g., Fietz, Touyz \& Hay, 2014; Tomba et al., 2014), however links with monitoring tool use in these domains have yet to be explored.

Moreover, little is known about user motives for engaging with food and activity monitoring devices, or indeed how these motives might be linked with compulsive exercise, psychological wellbeing and eating psychopathology. Previous research has found that motives for engaging in exercise and/or dieting that are primarily around controlling weight and shape, or in managing negative mood have been linked to more negative psychological outcomes in comparison to health-related motives (O'Brien et al., 2007; Vartanian, Wharton \& Green, 2012). Indeed, compulsive exercise has been linked to reduced quality of life and poorer psychological wellbeing in both clinical ED and community samples (Mond, Rodgers, Hay, Owen \& Beumont, 2004; Young et al., 2018). Exploring user motives and potential links with eating related psychopathology is therefore an important next step towards 
identifying user characteristics that could indicate an elevated risk of disordered eating and poorer mental health.

In summary, there is a small body of literature that has reported associations between food and activity monitoring tool use with body dissatisfaction and eating disorder symptoms (e.g., Embacher et al., 2018; Simpson and Mazzeo, 2017). However, this has yet to be extended to explore links with compulsive exercise cognitions or psychological wellbeing more broadly; disturbances which commonly occur alongside eating disorder symptoms. In addition, little is known about user motivations. Therefore, this study aims to (1) explore whether differences exist in levels of eating psychopathology, compulsive exercise and psychological wellbeing among users and non-users of activity and food intake monitoring tools; and (2) to assess if user profiles differ according to their reported motivations for using monitoring tools. It is predicted that levels of eating psychopathology and compulsive exercise will be significantly higher among users of activity and food intake monitoring tools compared to non-users. Specifically, it is anticipated that those who report using devices for body shape and/or weight reasons will score higher on measures of eating psychopathology and compulsive exercise than individuals who report using them for health or fitness related reasons. Finally, it is predicted that individuals who report using monitoring tools primarily to manage body shape and/or weight will score lower on a measure of psychological wellbeing than those who report using them for other reasons.

\section{Method}

\section{Participants}

Participants $(\mathrm{N}=352 ; 65 \%$ female $(\mathrm{n}=228) ; 82 \%$ White British; $\mathrm{n}=290)$ were recruited via opportunity sampling at a UK university campus, via a research participation scheme (in exchange for course credits) and via adverts on social media. The mean age of the 
sample was 21.90 years $(S D=3.24$; range $18-35 y r s)$ and the mean BMI was $22.87(S D=3.74$; range $15.78-39.45)$. Participants were able to provide their email addresses for entry into a draw to win a shopping voucher on completion of the study.

\section{Measures}

Compulsive Exercise Test (CET; Taranis, Touyz, \& Meyer, 2011). The CET is a 24-item self-report measure, comprising of five subscales: Avoidance and Rule Driven Behavior, Weight Control Exercise, Mood Improvement, Lack of Exercise Enjoyment and Exercise Rigidity. Higher scores indicate higher levels of compulsive exercise. All of the subscales were found to have good internal reliability ( $\alpha \geq .76)$, consistent with previous research (Meyer et al., 2016).

\section{Eating Disorder Examination Questionnaire (EDE-Q; Fairburn \& Beglin, 2008).} The EDE-Q is comprised of 28 items over four subscales (Restraint, Eating Concern, Shape Concern and Weight Concern). Participants report the frequency of eating attitudes and behaviors over the previous 28 days. Frequency of objective binge eating episodes (overeating associated with a loss of control) and purging (self-induced vomiting, laxative misuse, driven exercise) are also recorded. Reliability analysis indicated good reliability for the subscales $(\alpha \geq .81)$

\section{Warwick-Edinburgh Mental Wellbeing Scale (WEMWBS; Tennant et al, 2007).}

The WEMWBS is a 14-item self-report questionnaire, measuring mental wellbeing. Participants are asked to consider how they have been feeling over the last two weeks, and respond to statements (e.g., "I’ve been feeling good about myself') on a 5-point Likert scale from "None of the time" to "All of the time". Higher scores indicate better psychological well-being. The measure has been validated for use in both clinical (Bass, Dawkin, Muncer, Vigurs \& Bostock, 2016) and community populations (Tennant et al., 2007). The measure showed good internal consistency $(\alpha=.91)$; similar to previous research (Tennant et al, 2007). 
Inventory of weight-related monitoring tool use. Participants completed an inventory (developed by, and available from the authors) to provide information on their use of activity and food intake monitoring tools. The inventory was comprised of two main sections; part A, which focused on their use of activity monitoring devices; and part B, which focused on their use of food intake monitoring tools. Within each section, participants reported a) whether they used a device b) the type of device used; c) frequency of use; d) their main reasons for use (e.g., one from 'for physical health', 'for mental wellbeing'; 'to lose weight'; 'to build muscle/tone'; 'to burn calories'; 'to reach a step/activity target'; 'to achieve a sporting goal'; 'other') and e) responded to three questions about their perceptions of the tools (perceived helpfulness, level of concern if denied access, and the impact of the device on their activity or eating behaviors). The inventory is available from the authors on request.

\section{Procedure}

The study was approved by the institutional review board. Participants were provided with details about the study and were informed that the aim was to explore relationships between the use of activity and food monitoring tools with eating and exercise attitudes and psychological wellbeing. After providing informed consent, participants provided age, gender and self-reported height and weight data (to allow BMI to be calculated). They then completed the inventory of weight-related monitoring tool use; the CET; EDE-Q and WEMWBS (in that order). All responses were stored anonymously.

\section{Data Analysis}

EDE-Q subscales were found to be non-normally distributed, so non-parametric tests were used where applicable. Twenty-five participants reported only using food intake monitors, 117 used just activity monitoring devices and 87 used both activity and food intake monitors. Due to the small frequency of participants only using food intake monitoring tools, it was decided to combine the data into two groups (those who monitored; $\mathrm{n}=229$; and those 
who did not; $\mathrm{n}=123$ ) to address the first aim. Two-tailed tests of difference were conducted to explore differences between users and non-users of monitoring tools on the CET, EDE-Q and WEMWBS. Correlations were also conducted among users of monitoring tool to explore associations between the frequency of use with CET, EDE-Q and WEMWBS scores. Kruskal-Wallis, Chi-Square and Mann Whitney U analyses were conducted to address the second aim, and explore differences in EDE-Q, CET and WEMWBS scores and disordered eating behaviors in relation to reported reasons for using monitoring tools. Motives for use of activity and food intake monitoring tools were explored separately. All analyses were assessed using a $p$ value of $p \leq .01$ to control for multiple comparisons.

\section{Results}

\section{Sample characteristics}

Characteristics of the total sample, and for the two groups (monitoring tool users and non-users) are presented in Table 1. Scores on the EDE-Q, CET and WEMWBS were on par with other non-clinical, young adult samples (Mond, Hay, Rodgers \& Owen, 2006; Taranis et al., 2011; Tennant et al., 2007). The prevalence of binge eating and purging behaviors were similar to levels reported in other undergraduate cohorts (e.g., Lipson \& Somerville, 2017). Of those reporting purging behaviors $(n=94)$, the majority reported engaging in driven exercise $(n$ $=91 ; 97 \%)$, with small numbers of participants reporting self-induced vomiting $(n=6 ; 6.4 \%)$ and laxative misuse $(n=5 ; 5.3 \%)$.

Participants who used monitoring tools provided information about the frequency, reasons for use and the perceived helpfulness of the tools. The majority of users of activity $(69.7 \%)$ and food intake monitoring tools $(56.3 \%)$ reported using devices either daily or a few times a week. Participants also reported their primary reason for using an activity or food intake monitoring device. For users of activity devices, reasons for using monitoring tools were 
condensed into health and wellbeing related reasons (e.g., "for physical health", "for mental wellbeing"), weight and/or shape reasons (e.g., "to lose weight", "to build muscle/tone"; "to burn calories") and fitness or sporting goals (e.g., "to reach a step target"; "to achieve a sporting goal"). Most participants reported health and wellbeing-related reasons as their most important reason for using their activity monitoring device $(44 \% ; n=89)$, with $31 \%(n=62)$ reporting a weight or shape-related reason, and $25 \%(\mathrm{n}=50)$ reporting a goal-related reason. Among users of food intake monitoring tools, $30 \%(\mathrm{n}=31)$ reported using the device for health-related reasons (e.g., "to improve health and wellbeing"; "to improve energy levels") whilst the remainder of the sample reported using a food intake monitoring tool primarily to manage weight and/or shape $(70 \%, \mathrm{n}=73$; e.g., "to lose weight"; "to build muscle/tone"). The majority of activity (91\%) and food intake monitoring tool users $(85 \%)$ perceived the tools to be very or somewhat helpful in achieving their desired goals.

\section{Differences in eating psychopathology, compulsive exercise and wellbeing among users and non-users of monitoring tools}

Users of monitoring tools reported a higher BMI than non-users. Users also scored significantly higher two of the five CET-subscale scores (CET Weight Control Exercise, CET-Mood Improvement) and on three of the four EDE-Q subscales (EDE-Q-Restraint, EDE-Q Eating Concern, and EDE-Q-Weight Concern), with mostly small to moderate differences detected between the groups. Small, significant differences were identified in prevalence rates of any reported purging behaviors $\left(\chi^{2}(1)=12.53, p<.001, \mathrm{~V}=.19\right)$, and frequently reported purging behaviors $\left(\geq 4\right.$ times in the past 28 days; $\chi^{2}(1)=11.00, p=.001 ; \mathrm{V}$ $=.17$ ), with users of monitoring tools reporting higher levels compared to non-users. Among participants reporting any purging behaviors, 97\% of the users $(n=73)$ and all of the nonusers $(n=18)$ were purging via driven exercise. Among those reporting frequent purging 
behaviors, all of the users $(n=52)$ and non-users $(n=10)$ were purging via driven exercise.

No differences were observed between groups for binge eating behaviors or wellbeing scores.

\section{Associations between frequency of monitoring and eating psychopathology, compulsive exercise and wellbeing}

Among users of monitoring tools, a significant, moderate positive correlation was observed between the frequency of use of food intake and the frequency of use of activity monitoring devices $(r(87)=.46, p<.001)$. No significant correlations were observed between frequency of food intake monitoring and any CET, EDE-Q or wellbeing subscale ( $\mathrm{n}=112, r \leq$ $.13 ;$ Rho $\leq .23$, n.s). Small, significant positive correlations were observed between the frequency of use of activity monitoring tools with CET Weight Control Exercise scores $(r$ $(204)=.19, p<.01)$, and with EDE-Q Restraint and Weight Concern scores (Rho (204) $\geq .17$, $p \leq .01)$. No significant associations were found between binge eating or purging behaviors and frequency of activity or food intake monitoring.

\section{Reasons for using monitoring tools: Differences in eating psychopathology, compulsive exercise and wellbeing.}

Reported motives for activity monitoring. A significant, moderately-sized difference in CET Weight Control scores was identified according to reported reasons for use of monitoring tools $\left(\chi^{2}(2)=28.17 ; p<.001, \eta p^{2}=.12\right)$. As would be expected, participants who reported primarily using activity monitoring devices to manage weight and shape scored higher on CET Weight Control Exercise than those who reported using devices for other reasons. Participants who reported using activity monitoring devices to manage weight and shape also scored significantly higher (small to moderate effects) on some of the EDE-Q subscales in comparison to participants citing other reasons (notably, EDE-Q Restraint, Shape Concern and Weight Concern; $\chi^{2}(2) \geq 10.38 ; p \leq .01 ; \eta p^{2} \geq .05$; as seen in Table 2 ). 
Participants who reported primarily using monitoring tools to manage shape and weight $(n=32 ; 52 \%)$ reported significantly higher rates of purging behaviors than those who reported using the tools for health and fitness $(n=29 ; 33 \%)$ or to achieve a fitness/sporting goal $\left(\mathrm{n}=6,12 \% ; \chi^{2}(2)=19.61 ; p<.001 ; \mathrm{V}=.32\right)$. No significant differences in binge eating behaviors or wellbeing scores were observed according to reported reasons for activity monitoring.

Reported motives for food intake monitoring. Significant, small to moderate group differences were identified for CET Weight Control scores $(\mathrm{Z}=4.03 ; p \leq .01 ; r=.40)$, and EDEQ Shape Concern and Weight Concern scores $(\mathrm{Z} \geq 2.90 ; p \leq .01 ; r \geq .28$; Table 3$)$. Specifically, participants who reported using food intake monitoring tools to manage weight and shape showed significantly higher scores compared to those citing health-related reasons. No significant differences were detected for the prevalence of binge eating or purging behaviors, or for wellbeing scores according to reported reasons for food intake monitoring.

\section{Discussion}

This study had two aims: (1) to explore whether differences exist in levels of eating psychopathology, compulsive exercise and psychological wellbeing among users and nonusers of activity and food intake monitoring tools; and (2) to assess if user profiles differ according to their reported motivations for using monitoring tools. Users of monitoring tools were reported higher levels of dietary restraint and concerns about eating and weight compared to non-users, which is consistent with previous research (e.g., Embacher et al., 2018; Simpson \& Mazzeo, 2017). Novel outcomes emerged in relation to the increased prevalence of purging behaviors (specifically driven exercise) and the higher levels of compulsive exercise reported by users of monitoring tools. Small positive associations were identified between frequency of activity monitoring and levels of compulsive exercise and 
eating psychopathology. Participants who reported using monitoring tools primarily for weight and shape purposes reported higher levels of pathology (dietary restraint, concerns over weight and shape, exercising for weight control, and purging behaviors) than those who reported using the tools for health-related reasons. It is, however, noted that the magnitude of these effects were mostly small.

The results of this cross-sectional study could simply reflect that participants with disordered eating and compulsive exercise tendencies may be more likely to engage in monitoring of food intake and exercise behavior. Alternatively, it is possible that selfmonitoring of food intake and activity could inadvertently validate features of compulsive exercise among vulnerable individuals (e.g., obsessive and rigid exercise attitudes and behaviors; Meyer, Taranis, Goodwin and Haycraft, 2011). However, causal relationships between monitoring tool use and features of eating and exercise psychopathology can't be inferred from this study; therefore, it is essential that future research in this area adopts prospective and experimental designs to generate further understanding of the mechanisms underpinning the observed associations. It will also be important to identify and prospectively explore aspects of device feedback that may be particularly salient to users (e.g., number of steps, calories burned) and to differentiate between monitoring of food intake and activity behaviors. Due to small numbers of participants exclusively using food intake devices, comparisons between food intake and activity monitoring tool users were not possible in this study. It will also be important to consider the role of other potentially important explanatory variables (e.g., self-critical perfectionism; gender; age).

No differences in psychological wellbeing were reported between users and nonusers; or according to reported reasons for using monitoring tools. This contrasts with previous literature that has identified more negative psychological outcomes among those who report dieting or exercising for weight-related motives in comparison to health-related 
motives (O’Brien et al., 2007; Vartanian et al., 2012), and reduced quality of life among individuals with compulsive exercise and eating psychopathology (Mond et al., 2004; Young et al., 2018). It is plausible to suggest that any negative effects of monitoring are off-set by increases in feelings of physical wellness, perhaps as a result of changes to physical activity, dietary practices or as a result of observing progress towards one's goal. Indeed, most users in this study perceived monitoring tools to be helpful in achieving their desired goals. Goal attainment is an important contributing factor for psychological wellbeing (e.g., Sheldon \& Elliot, 1999), and can be facilitated by self-monitoring (Harkin et al., 2016). Furthermore, users of monitoring tools in this study endorsed exercising for mood improvement more so than non-users, which may serve to moderate any negative impacts of monitoring on wellbeing; however, further research is needed to identify for whom, and in what circumstances monitoring may be beneficial or harmful. Future studies may consider including specific measures of depression and/or anxiety, to allow for a more nuanced evaluation of links between psychological wellbeing and monitoring tool use.

Elevated levels of attitudinal aspects of eating psychopathology (notably, dietary restraint, weight and shape concern) and increased purging behaviors were reported among those who endorsed using devices for weight and shape reasons; however, no differences were reported for binge eating. The reported levels of binge eating in the sample were high, (although on par with other student samples; e.g., Lipson \& Sonneville, 2017), which contrasted with the comparatively lower levels of attitudinal psychopathology (Mond et al., 2006; Taranis et al., 2011; Tennant et al., 2007). Some sampling biases may have occurred, as the study aim was disclosed to participants at recruitment as part of informed consent. Self-report assessments, particularly for the behavioral aspects of disordered eating can generate elevated scores and are potentially unreliable due to differences in participants' interpretation of items measuring binge eating (Goldschmidt, 2017; Mond, Hay, Rodgers, 
Owen \& Beumont, 2004; Reslan \& Saules, 2011), which could have impacted upon the findings. In addition, the measure of monitoring tool use was developed for the purpose of the study and would benefit from further validation. Specifically, it will be important to explore potential social desirability influences on reported motives for use of monitoring tools.

Moreover, the vast majority of reported 'purging' behavior was via driven exercise, with very few participants reporting other forms of purging. Exercise may be considered a more socially acceptable method of weight control and emotion regulation. However, recent evidence has highlighted the seriousness of driven exercise, even when it occurs in the absence of binge eating or other purging behaviors; 'driven exercisers' were found to report equivalent levels of eating psychopathology as those who reported purging via other mechanisms (Lydecker, Shea \& Grilo, 2018). Further exploration is needed to identify if, and how monitoring tool use is linked to driven exercise behavior. Gold standard interviews should be employed to more accurately ascertain behavioral and attitudinal features of eating psychopathology (e.g., Eating Disorders Examination, Fairburn \& Cooper, 1993), and clinical populations should be included for comparison.

For many, monitoring food and exercise activity is likely to be a helpful mechanism by which to achieve positive behavior change (Samdal et al., 2017). However, the findings of this study suggest it may be pertinent to provide guidance around the safe use of monitoring tools to young people, teachers and parents. Similarly, it may be useful to incorporate questions around the use of monitoring tools into screening for eating psychopathology and compulsive exercise. Companies developing such technologies may consider including a preuse screen to identify motivational factors and work alongside eating disorder professionals to provide appropriate in-app signposting and support. 
In summary, this study extends our existing understanding of the associations between the use of monitoring tools with eating psychopathology, compulsive exercise and psychological wellbeing. It is the first known study to explore how reported motives for use of monitoring tools are related to features of eating psychopathology and compulsive exercise. The findings suggest that users of food intake and activity monitoring tools (and particularly those reporting using them for weight and shape purposes) may be an important group for targeted intervention. It may be pertinent to consider the provision of guidance around the use of monitoring tools, and to include questions around monitoring tool use when screening for eating psychopathology and compulsive exercise. Future longitudinal and experimental research in this area is essential to further our understanding of the dynamic relationships between monitoring, compulsive exercise and eating psychopathology. 


\section{References}

Alley, S., Schoeppe, S., Guertler, D., Jennings, C., Duncan, M.J., Vandelanotte, C (2016). Interest and preferences for using advanced physical activity tracking devices: Results of a national cross-sectional survey. BMJ Open, 6, e011243. Doi: 10.1136/bmjopen2016-011243.

Bardone-Cone, A.M., Wonderlich, S.A., Frost, R.O., Bulik, C.M., Mitchell, J.E., Uppala, S., \& Simonich, H. (2007). Perfectionism and eating disorders: Current status and future directions. Clinical Psychology Review, 27(3), 384-405. Doi: 10.1016/j.cpr.2006.12.005.

Bass, M., Dawkin, M., Muncer, S., Vigurs, S., Bostock, J. (2016). Validation of the Warwick-Edinburgh Mental Well-being Scale (WEMWBS) in a population of people using Secondary Care Mental Health Services. Journal of Mental Health, 25(4), 323329. Doi: $10.3109 / 0963827.2015 .1124401$

Carver, C.S., \& Scheier, M.F. (1982). Control theory: A useful conceptual framework for personality-social, clinical and health psychology. Psychological Bulletin, 92(1), 111135.

De Cock, N., Vangeel, J., Lachat, C., Beullens, K., Vervoort, L., Goosens, L... \& Lippevelde, W.V. (2017). Use of fitness and nutrition apps: Associations with body mass index, snacking and drinking habits in adolescents. JMIR mHealth and uHealth 5(4), e58. Doi: 10.2196/mhealth.6005.

Embacher, K., McGloing, R., \& Atkin, D. (2018). Body dissatisfaction, neuroticism and female sex as predictors of calorie-tracking app use amongst college students. Journal of American College Health, Doi: 10.1080/07448481.2018.1431905 
Fairburn, C.G., \& Cooper, Z. (1993). The eating disorder examination (12 ${ }^{\text {th }}$ edition). In C.G. Fairburn, \& G.T. Wilson (Eds.) Binge Eating: Nature, assessment and treatment (pp.317-360). New York: Guilford Press.

Fairburn. C.G., Cooper, Z., \& Shafran, R. (2003). Cognitive behavior therapy for eating disorders: A "transdiagnostic" theory and treatment. Behavior Research and Therapy, 41(5), 509-528. Doi: 10.1016/S0005-7967(02)00088-8.

Fietz, M., Touyz, S., \& Hay, P. (2014). A risk profile of compulsive exercise in adolescents with an eating disorder: A systematic review. Advances in Eating Disorders: Theory, Research and Practice, 2(3), 241-263. Doi: 10.1080/21662630.2014.894470.

Fox, S., \& Duggan, M. (2012). Mobile Health. Pew Research Center's Internet and American Life Project. Retrieved $1^{\text {st }}$ May 2018 from:

\section{http://www.pewinternet.org/2012/11/08/mobile-health-2012/}

Goldschmidt, A.B. (2017). Are loss of control while eating and overeating valid constructs? A critical review of the literature. Obesity Reviews, 18(4), 112-119. Doi: 10.1111/obr.12491

Harkin, B., Webbm T.L., Chang, B.P.I., Prestwich, A., Conner, M., Kellar, I...\& Sheeran, P. (2016). Does monitoring goal progress promote goal attainment? A meta-analysis of the experimental evidence. Psychological Bulletin, 142(2), 198-229. Doi: $10.1037 / \mathrm{bul} 0000025$.

International Data Corporation (IDC; 2016). Fitness trackers in the lead as wearables market grows $3.1 \%$, according to IDC. Retrieved $17^{\text {th }}$ May 2018 from: https://www.idc.com/getdoc.jsp?containerId=prUS41996116 
Lee, H.E., \& Cho, J. (2017). What motivates users to continue using diet and fitness apps? Application of the uses and gratifications approach. Health Communication, 32(12), 1445-1453. Doi: 10.1080/10410236.2016.1167998.

Levinson, C.A., Fewell, L., \& Brosof, L.C. (2017). My Fitness Pal calorie tracker usage in the eating disorders. Eating Behaviors, 27, 14-16. Doi: 10.1016/j.eatbeh.2017.08.003

Lipson, S.K., \& Somerville, K.R. (2017). Eating disorder symptoms among undergraduate and graduate students at 12 U.S. colleges and universities. Eating Behaviors, 24, 81-88. Doi: 10.1016/j.eatbeh.2016.12.003.

Lydecker, J.A., Shea, M., \& Grilo, C.M. (2018). Driven exercise in the absence of binge eating: Implications for purging disorder. International Journal of Eating Disorders, 51, 139-145. Doi: 10.1002/eat.22811

Krebs, P., \& Duncan, D.T. (2015). Health app use among US mobile phone owners: A national survey. JMIR mHealth and whealth 3(4), e101. Doi: 10.2196/mhealth.4924.

Meyer, C., Plateau, C.R., Taranis, L., Brewin, N., Wales, J., \& Arcelus, J. (2016). The Compulsive Exercise Test: Confirmatory factor analysis and links with eating psychopathology among women with clinical eating disorders. Journal of Eating Disorders, 4:22. Doi: 10.1186/s40337-016-0113-3.

Meyer, C., Taranis, L., Goodwin, H., \& Haycraft, E. (2011). Compulsive exercise and eating disorders. European Eating Disorders Review, 19(3), 174-189. Doi: 10.1002/erv.1122.

Mond, J.M., Hay, P.J., Rodgers, B., \& Owen, C. (2006). Eating Disorder Examination Questionnaire (EDE-Q): Norms for young adult women. Behavior Research and Therapy, 44(1), 53-62. Doi: 10.1016/j.brat.2004.12.003 
Mond, J.M., Hay, P.J., Rodgers, B., Owen, C. \& Beumont, P.J.V. (2004). Validity of the EDE-Q in screening for eating disorders in community samples. Behavior Research and Therapy, 42(5) 551-567. Doi: 10.1016/S0005-7967(03)00161-X

Mond, J.M., Rodgers, B., Hay, P.J., Owen, C., Beumont, P.J.V. (2004). Relationships between exercise behavior, eating-disordered behavior and quality of life in a community sample: When is exercise 'excessive'? European Eating Disorders Review, 12, 265-272. Doi: 10.1002/erv.579

Neumark-Sztainer, D., Paxton, S.J., Hannan, P.J., Haines, J., \& Story, M. (2006). Does body dissatisfaction matter? Five-year longitudinal associations between body satisfaction and health behaviors in adolescent females and males. Journal of Adolescent Health, 39(2), 244-251. Doi: 10.1016/j.jadohealth.2005.12.001.

O’Brien, K., Venn, B.J., Perry, T., Green, T.J., Aitken, W., Bradshaw, A., \& Thomson, R. (2007). Reasons for wanting to lose weight: Different strokes for different folks. Eating Behaviors, 8, 132-135. Doi 10.1016/j.eatbeh.2006.01.004.

Reslan, S., \& Saules, K.K. (2011). College students' definition of an eating “binge” differ as a function of gender and binge eating disorder status. Eating Behaviors, 12(3), 225-227. Doi: 10.1016/j.eatbeh.2011.03.001.

Samdal, G.B., Eide, G.E., Barth, T., Williams, G., \& Meland, E. (2017). Effective behavior change techniques for physical activity and healthy eating in overweight and obese adults; systematic review and meta-regression analyses. International Journal of Behavioral Nutrition and Physical Activity, 14:42. Doi: 10.1186/s12966-017-0494-y.

Sarcona, A., Kovacs, L., Wright, J., \& Williams, C. (2017). Differences in eating behavior, physical activity and health-related lifestyle choices between users and non-users of 
mobile health apps. American Journal of Health Education, 45(5), 298-305. Doi: $10.1080 / 19325037.2017 .1335630$.

Shafran, R., Cooper, Z., \& Fairburn, C.G. (2002). Clinical perfectionism: A cognitive behavioral analysis. Behavior Research and Therapy, 40, 773-791. Doi: 10.1016/S0005-7967(01)00059-6

Sheldon, K.M., \& Elliot, A.J. (1999). Goal striving, need satisfaction, and longitudinal wellbeing: The self-concordance model. Journal of Personality and Social Psychology, 76(3), 482-497. Doi: 10.1037/0022-3514.76.3.482.

Simpson, C.C., \& Mazzeo, S.E. (2017). Calorie counting and fitness tracking technology: Associations with eating disorder symptomatology. Eating Behaviors, 26, 89-92. Doi: 10.1016/j.eatbeh.2017.02.002.

Taranis, L., Touyz, S., \& Meyer, C. (2011). Disordered eating and exercise: Development and preliminary validation of the Compulsive Exercise Test. European Eating Disorders Review, 19(3), 256-268. Doi: 10.1002/erv.1108.

Tennant, R., Hiller, L., Fishwick, R., Platt, S., Joseph, S., Weich, S... \& Stewart-Brown, S. (2007). The Warwick-Edinburgh Mental Well-being scale (WEMWBS): Development and UK validation. Health and Quality of Life Outcomes,5:63. Doi: 10.1186/1477$7525-5-63$

Tomba, E., Offidani, E., Tecuta, L., Schumann, R., Ballardini, D. (2014). Psychological wellbeing in out-patients with eating disorders: A controlled study. International Journal of Eating Disorders, 47(3), 252-258. Doi: 10.1002/eat.22197. 
Vartanian, L.R., Wharton, C.M., Green. E.B. (2012). Appearance vs. health motives for exercise and for weight loss. Psychology of Sport and Exercise, 13(3), 251-256. Doi: 10.1016/j.psychsport.2011.12.005.

Young, S., Touyz, S., Meyer, C., Arcelus, J., Rhodes, P., Madden, S..\& Hay, P. (2018). Relationships between compulsive exercise, quality of life, psychological distress and motivation to change in adults with anorexia nervosa. Journal of Eating Disorders, 6(2). Doi: 10.1186/s40337-018-0188 
Table 1: Descriptive information for users and non-users of activity and food intake monitoring tools.

\begin{tabular}{|c|c|c|c|c|c|}
\hline & $\begin{array}{l}\text { Total sample } \\
(\mathrm{N}=352)\end{array}$ & $\begin{array}{l}\text { Users } \\
(n=229)\end{array}$ & $\begin{array}{l}\text { Non-users } \\
(\mathrm{n}=\mathbf{1 2 3})\end{array}$ & $\mathrm{Z} / \mathrm{t} / \chi^{2}$ & $\begin{array}{l}\text { Effect } \\
\text { size }\end{array}$ \\
\hline Gender & $\begin{array}{l}65 \% \text { female }(\mathrm{n}= \\
228)\end{array}$ & $\begin{array}{l}69 \% \text { female }(\mathrm{n}= \\
158)\end{array}$ & $\begin{array}{l}57 \% \text { female } \\
(\mathrm{n}=70)\end{array}$ & - & - \\
\hline Age & $21.90(3.24)$ & $22.01(3.35)$ & $21.77(3.13)$ & .66 & .07 \\
\hline BMI & $22.87(3.74)$ & $23.23(4.02)$ & $22.19(3.03)$ & $2.46^{*}$ & .29 \\
\hline CET Avoidance & $1.79(1.03)$ & $1.85(1.06)$ & $1.68(.98)$ & 1.44 & .17 \\
\hline CET Weight Control Exercise & $2.57(1.15)$ & $2.75(1.10)$ & $2.21(1.17)$ & $4.28 * *$ & .48 \\
\hline CET Mood Improvement & $3.22(1.00)$ & $3.31(.94)$ & $3.04(1.08)$ & $2.49 *$ & .27 \\
\hline CET Lack of Exercise Enjoyment & $1.64(1.10)$ & $1.62(1.09)$ & $1.67(1.11)$ & .39 & .05 \\
\hline CET Exercise Rigidity & $2.75(1.20)$ & $2.83(1.18)$ & $2.61(1.23)$ & 1.68 & .18 \\
\hline EDE-Q Restraint & $1.17(1.25)$ & $1.39(1.30)$ & $.75(1.04)$ & $4.97 * *$ & .26 \\
\hline EDE-Q Eating Concern & $.66(1.01)$ & $.74(1.04)$ & $.50(.94)$ & $2.78 *$ & .15 \\
\hline EDE-Q Shape Concern & $2.02(1.60)$ & $2.14(1.61)$ & $1.81(1.55)$ & 1.85 & .10 \\
\hline EDE-Q Weight Concern & $1.71(1.52)$ & $1.87(1.53)$ & $1.42(1.47)$ & $2.93 *$ & .16 \\
\hline Binge eating $(\mathrm{n} ; \%)$ & $138(39 \%)$ & $96(42 \%)$ & $42(34 \%)$ & 1.83 & .07 \\
\hline $\begin{array}{l}\text { Binge eating } \geq 4 \text { times in the past } \\
28 \text { days }\end{array}$ & $72(20 \%)$ & $51(22 \%)$ & $21(17 \%)$ & 1.22 & .06 \\
\hline Purging (n; \%) & $93(26 \%)$ & $75(33 \%)$ & $18(15 \%)$ & $12.53 * *$ & .19 \\
\hline $\begin{array}{l}\text { Purging } \geq 4 \text { times in the past } 28 \\
\text { days }\end{array}$ & $62(18 \%)$ & $52(23 \%)$ & $10(8 \%)$ & $11.00 * *$ & .17 \\
\hline $\begin{array}{l}\text { Warwick-Edinburgh Mental } \\
\text { Wellbeing Scale }\end{array}$ & $48.99(8.28)$ & $48.72(8.50)$ & $49.48(7.86)$ & .81 & .09 \\
\hline
\end{tabular}


MONITORING EATING AND ACTIVITY

Table 2: Differences in CET, EDE-Q and WEMWBS scores according to reasons for use of activity monitoring tools

\begin{tabular}{|c|c|c|c|c|c|c|c|c|}
\hline & \multicolumn{8}{|c|}{ Primary reason for monitoring activity } \\
\hline & \multicolumn{2}{|c|}{$\begin{array}{l}\text { To manage weight/ shape } \\
(\mathrm{W}, \mathbf{n}=89)\end{array}$} & \multicolumn{2}{|c|}{$\begin{array}{l}\text { To improve health and } \\
\text { wellbeing }(H, n=62)\end{array}$} & \multicolumn{2}{|c|}{$\begin{array}{l}\text { To achieve a fitness/ sporting } \\
\text { goal }(\mathrm{F}, \mathrm{n}=\mathbf{5 0})\end{array}$} & \multirow[t]{2}{*}{$\begin{array}{c}\text { Kruskal Wallis } \chi^{2} \\
\left(\eta p^{2}\right)\end{array}$} & \multirow[t]{2}{*}{$\begin{array}{l}\text { Sig Pairwise } \\
\text { comparisons }\end{array}$} \\
\hline & $\mathbf{M}$ & SD & $\mathbf{M}$ & SD & $\mathbf{M}$ & SD & & \\
\hline CET Weight Control Exercise & 3.34 & .92 & 2.55 & 1.13 & 2.37 & 1.03 & $28.17 * *(.12)$ & $\mathrm{W}>\mathrm{H} ; \mathrm{W}>\mathrm{F}$ \\
\hline CET Avoidance & 1.84 & 1.03 & 1.95 & 1.08 & 1.63 & 1.08 & $2.57(.01)$ & - \\
\hline CET Mood Improvement & 3.41 & .96 & 3.41 & .88 & 3.12 & 1.04 & $2.99(.01)$ & - \\
\hline CET Lack of Exercise Enjoyment & 1.66 & 1.11 & 1.40 & .85 & 1.76 & 1.30 & $1.90(.01)$ & - \\
\hline CET Exercise Rigidity & 2.91 & 1.29 & 2.99 & 1.06 & 2.40 & 1.18 & $7.80(.04)$ & - \\
\hline EDEQ Restraint & 1.78 & 1.45 & 1.16 & 1.14 & 1.06 & 1.21 & $10.38 *(.05)$ & $\mathrm{W}>\mathrm{H} ; \mathrm{W}>\mathrm{F}$ \\
\hline EDE-Q Eating Concern & $1.05^{\mathrm{a}}$ & 1.18 & $.66^{\mathrm{a}}$ & 1.12 & .58 & .75 & $6.60(.03)$ & - \\
\hline EDE-Q Shape Concern & 2.91 & 1.71 & 1.78 & 1.47 & 1.67 & 1.45 & $20.46 * *(.09)$ & $\mathrm{W}>\mathrm{H} ; \mathrm{W}>\mathrm{F}$ \\
\hline EDE-Q Weight Concern & 2.58 & 1.65 & 1.60 & 1.38 & 1.45 & 1.49 & $18.62 * *(.09)$ & $\mathrm{W}>\mathrm{H} ; \mathrm{W}>\mathrm{F}$ \\
\hline WEMWBS & 47.95 & 8.73 & 48.75 & 8.44 & 50.14 & 8.34 & $1.58(.01)$ & - \\
\hline BMI & 24.13 & 4.21 & 22.74 & 3.80 & 22.81 & 4.14 & $5.38(.03)$ & - \\
\hline
\end{tabular}

${ }^{*} p \leq .01{ }^{* *} p \leq .001$ 
Table 3: Differences in CET, EDE-Q and WEMWBS scores according to reasons for use of food intake monitoring tools.

\section{Primary reason for monitoring food intake}

\begin{tabular}{|c|c|c|c|c|c|c|}
\hline & \multicolumn{2}{|c|}{$\begin{array}{l}\text { Weight related reasons } \\
(n=73)\end{array}$} & \multicolumn{3}{|c|}{$\begin{array}{l}\text { Health-related reasons } \\
(\mathrm{n}=\mathbf{3 1})\end{array}$} & \multirow[b]{2}{*}{ Effect size } \\
\hline & $\mathbf{M}$ & SD & $\mathbf{M}$ & SD & $\mathbf{Z}$ & \\
\hline CET Weight Control Exercise & 3.24 & 1.00 & 2.39 & .90 & 4.03* & .40 \\
\hline CET Avoidance & 2.11 & 1.12 & 1.86 & 1.01 & .89 & .09 \\
\hline CET Mood Improvement & 3.45 & .88 & 3.27 & .90 & .91 & .09 \\
\hline CET Lack of Exercise Enjoyment & 1.73 & 1.10 & 1.46 & 1.02 & 1.07 & .11 \\
\hline CET Exercise Rigidity & 3.00 & 1.16 & 3.00 & 1.10 & .05 & .00 \\
\hline EDEQ Restraint & 1.93 & 1.36 & 1.46 & 1.15 & 1.68 & .16 \\
\hline EDE-Q Eating Concern & 1.04 & 1.15 & .77 & 1.16 & 1.30 & .13 \\
\hline EDE-Q Shape Concern & 2.94 & 1.76 & 1.87 & 1.44 & $2.90 *$ & .28 \\
\hline EDE-Q Weight Concern & 2.63 & 1.62 & 1.46 & 1.37 & $3.41 *$ & .33 \\
\hline WEMWBS & 47.18 & 9.40 & 68.00 & 9.94 & 1.11 & .11 \\
\hline BMI & 24.24 & 4.47 & 22.69 & 4.81 & 2.31 & .23 \\
\hline
\end{tabular}

$* p \leq .01 * * p<.001$ 